\title{
Ionic Liquid Assisted Electrospun Cellulose Acetate Fibers for Aqueous Removal of Triclosan
}

\author{
Gong Zhang, ${ }^{\dagger, \S}$ Meng Sun, ${ }^{\dagger, \S}$ Yang Liu, ${ }^{\ddagger}$ Huijuan Liu, ${ }^{*}{ }^{\dagger}$ Jiuhui Qu, ${ }^{\dagger}$ and Jinghong Li ${ }^{*}$,
}

${ }^{\dagger}$ Key Laboratory of Drinking Water Science and Technology, Research Center for Eco-Environmental Sciences, Chinese Academy of Sciences, Beijing 100085, China

${ }^{\ddagger}$ Department of Chemistry, Beijing Key Laboratory for Microanalytical Methods and Instrumentation, Tsinghua University, Beijing 100084, China

${ }^{\S}$ University of Chinese Academy of Sciences, Beijing 100039, China

\section{Supporting Information}

ABSTRACT: The cellulose acetate (CA) membrane prepared via electrospun was innovatively utilized as fiber-adsorbent for the separation of aqueous triclson (TCS). It was found that the presence of the room temperature ionic liquid (RTIL) in the precursor amplified electric force toward the CA-solution, thereby benefiting the formation of CA fibers. The as-spun CA fibers exhibit excellent adsorptive performance toward TCS, with fast adsorption kinetics, and the maximum adsorption capacity achieved to $797.7 \mathrm{mg} \mathrm{g}^{-1}$, which established much better performance in contrast to conventional adsorbents. We proposed that the adsorption of TCS onto CA fibers was primarily facilitated by the hydrogen bonding between the abundant carbonyl, hydroxyl groups of CA surface, and the hydrogen atoms of phenol functional groups in TCS molecular.

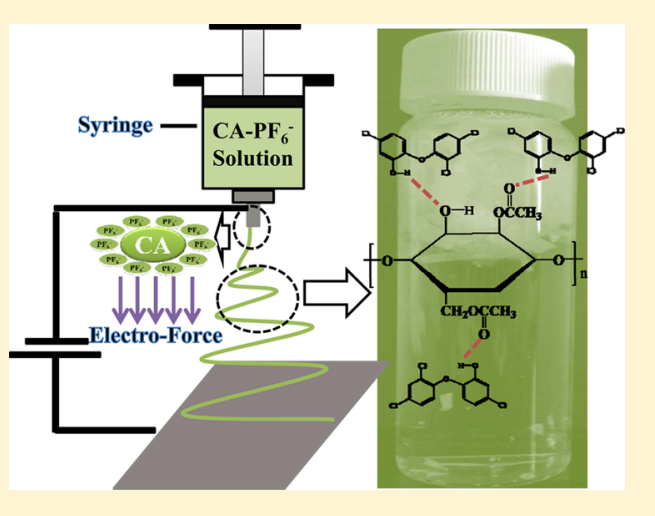

\section{INTRODUCTION}

Cellulose acetate (CA) is the acetate ester of cellulose, the primary structural component of the cell wall of green plants and one of the most common biopolymers on earth. ${ }^{1}$ Compared to powders, fibers with widths in the nanometer range display higher surface energy and improved reactivity. Electrospinning is a versatile technique which utilizes high electrostatic forces for fiber production. Four major components are required for electrospinning: a direct current power supply, a metallic needle with a blunt-tip, a syringe for to contain precursor, and a grounded conductive collector. Polymer concentration, solution viscosity, electric field intensity, and air humidity influence the fiber formation process. ${ }^{2-6}$ However, the lack of solubility of CA in nonvolatile organic solvents constitutes an obstacle for electrospinning CA fibers. Therefore, many attempts have employed polar organic compounds as solvents. ${ }^{7-9}$ However, due to rapid evaporation, this swiftly led to clogging at the tip of the nozzle, terminating the electrospinning process. Currently, some works involved adding the room temperature ionic liquid (RTIL) to a precursor for electrospinning fibers. ${ }^{10-12}$ RTILs are organic compounds consisting entirely of ions that exist in a liquid state around room temperature. ${ }^{13,14}$ Therefore, the entrapment of RTIL creates IL-based solutions that can amplify the electric force applied to the polymer. As a result, production of fibers takes place at a faster rate than evaporation of solvent at the tip of the needle, enabling continuous formation of fibers.
Triclosan (TCS), first introduced to the market in $1964,{ }^{15}$ a member of the class of pharmaceutical and personal care products (PPCPs), acts as a broad-spectrum antimicrobial and preserving agent. Approximately $1500 \mathrm{t}$ of TCS is produced annually worldwide, ${ }^{16}$ and up to $96 \%$ of TCS is washed into the sewage systems during normal use, eventually entering the aquatic environment. ${ }^{17}$ Furthermore, TCS and its transformation products have been found to pose a threat to human health. ${ }^{18-22}$ Therefore, efficient treatment technologies for the removal of TCS and its derivative products from the environment have become of great concern. Studies on treatment of drinking water and wastewater for TCS removal through conventional treatment processes have found them to be not totally effective. ${ }^{23}$ Recently, researchers have proposed that biological degradation of TCS takes place under aerobic and anaerobic conditions. However, a relatively slow degradation rate and long biodegradation half-life destine this approach to failure. ${ }^{24}$ Photocatalytic degradation of TCS has drawn attention as well; ${ }^{24-26}$ however, high cost and concerns about degradation products restrain its practical use. Several researchers have revealed that adsorption can play an important role in the removal of TCS. ${ }^{27-29}$ Behera et al. ${ }^{28}$ studied the TCS sorption capacity of activated carbon, kaolinite, and montmorillonite. Cho et al. ${ }^{30}$ studied the effects of solution

Received: September 28, 2014

Revised: December 31, 2014

Published: January 16, 2015 
Scheme 1. Representation of the Electrospinning Setup for Producing the CA Fibers

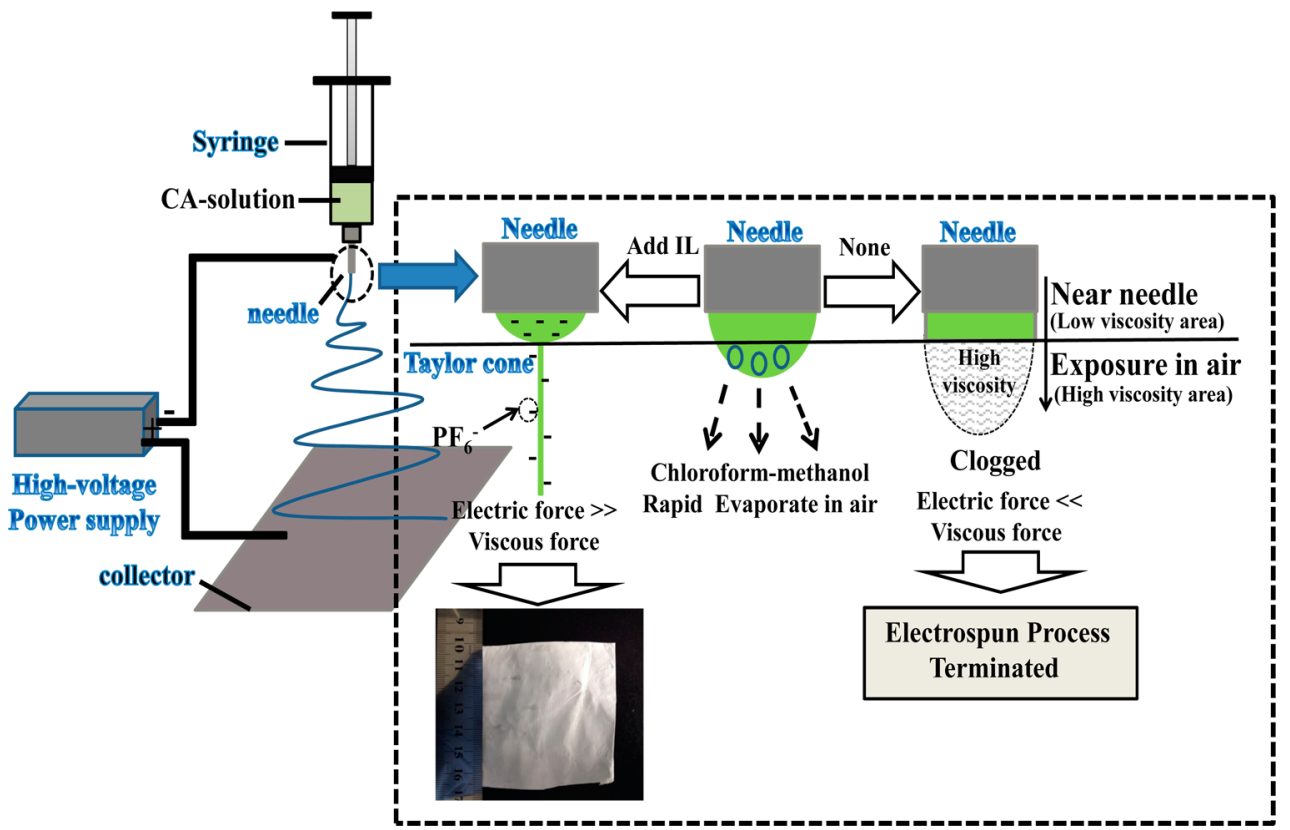

chemistry on the adsorption of TCS, and a sorption capacity up to $105.02-558.26 \mathrm{mg} \mathrm{g}^{-1}$ was found for carbon nanotubes. Considering the advantages of applicability at low concentrations, ease of operation, and the absence of byproducts requiring removal, the search for environmentally benign adsorbents to remove TCS and understanding the adsorptive mechanism are of great importance.

Cellulose acetate (CA) containing TCS molecules is widely applied to prevent bacterial growth or infection in medical treatment, ${ }^{31,32}$ and its stable character suggests to us that the TCS molecules should be strongly bound onto the polymer. Inspired by this, we prepared the electrospinning CA fibers via addition of an ionic liquid. The as-spun CA fibers were utilized to separate TCS from aqueous solution, and the sorption kinetics and capacity were evaluated. In addition, the functional groups and molecular properties of CA fibers and TCS were studied thoroughly, to reveal the adsorption mechanism between the CA and TCS.

\section{EXPERIMENTAL SECTION}

Materials. Two varieties of cellulose acetate (acetyl content $=55 \%$ $(\mathrm{w} / \mathrm{w})$ and $30 \%(\mathrm{w} / \mathrm{w}))$ were purchased from Sinopharm (Shanghai) Chemical Reagent Co., Ltd, China. Triclosan (reagent grade) was purchased from Sigma-Aldrich Corporation. For the adsorption experiments, a stock solution of TCS was prepared by dissolving TCS powder into HPLC grade methanol. 1-Butyl-3-methylimidazolium hexafluorophosphate $\left(\mathrm{BMIPF}_{6}\right)$ was used as the ionic liquid, and the conductivity of pure $\mathrm{BMIPF}_{6}$ was $1.4 \times 10^{-3} \mathrm{~S} \mathrm{~cm}^{-1}$. Other reagents were of analytical grade, used without further purification.

Preparation of Electrospun CA Fibers. Electrospinning technology was used for fabrication of CA fibers. The precursor used for electrospinning was prepared as follows: $0.90 \mathrm{~g}$ of cellulose acetate was added to $10 \mathrm{~mL} \mathrm{4:1} \mathrm{chloroform/methanol} \mathrm{mixture} \mathrm{to}$ obtain a homogeneous CA solution with the aid of stirring and sonication. Afterward, $1 \%$ vol of $\mathrm{BMIMPF}_{6}$ was added to the above solution under vigorous stirring to obtain a homogeneous CA-BMIPF solution as the precursor. Next, the solution was loaded into a glass syringe equipped with a blunt stainless steel needle, connected to a 15 $\mathrm{kV}$ high voltage supply. Solution was fed at a rate of $3 \mathrm{~mL} \mathrm{~h}^{-1}$ using a syringe pump. A stainless steel drum was placed under the tip of the needle as to collect fibers. The specific operation process is shown in
Scheme 1. Last, this as-spun product was washed by distilled water and dried in oven at $80^{\circ} \mathrm{C}$ overnight.

Characterization of the CA Fibers. The morphology of CA fibers was observed using a Hitachi field-emission scanning electron microscope (FESEM) combined with an energy dispersive spectrometer (EDS) to analyze the elemental composition. In addition, JEOL high-resolution electron microscopy (HRTEM) was used to obtain the specific pore distribution directly, and the pore structure and specific surface of the as-spun fibers were further determined by $\mathrm{N}_{2}$ adsorption at $77 \mathrm{~K}$ using the volumetric method on an automatic adsorption instrument. The FTIR spectra were obtained on Bruker Spectrum spectrometer (Germany). Surface composition of the fibers was analyzed by X-ray photoelectron spectroscopy (XPS) using $\mathrm{Al} \mathrm{K} \alpha$ $(1486.7 \mathrm{eV})$ as radiation source. The binding energy of the XPS spectra was calibrated with reference to the $\mathrm{C} 1 \mathrm{~s}$ peak at $284.8 \mathrm{eV}$. Functional groups of the CA fibers were identified by solid-state ${ }^{13} \mathrm{C}$ cross-polarization/magic angle spin (CP/MAS) NMR spectra collected on a Bruker $400 \mathrm{MHz}$ spectrometer equipped with tripleresonance, $z$-axis gradient cryoprobe, BACS-120 sample changer, and Icon NMR software for automated data collection. Water contact angles were measured on a Dataphysics OCA20 contact-angle system (Germany).

Sorption Experiments. Experiments were conducted in $50 \mathrm{~mL}$ amber glass vials. Into each vial, $40 \mathrm{mg}$ CA electrospun fibrous membrane was added and vials were then filled with $40 \mathrm{~mL}$ of TCScontaining solution. The solution was prepared by transferring a precise volume of TCS/methanol from a stock solution into an aqueous solution containing $3.0 \mathrm{mM} \mathrm{NaN}_{3}$ (to prevent bacterial growth) and $10.0 \mathrm{mM} \mathrm{NaCl}$ (to increase ionic strength). To minimize cosolvent effects, the maximum initial concentration of TCS was set at $25 \mathrm{mg} \mathrm{L}^{-1}$ and the volume of methanol added in each vial did not exceed $0.1 \% \mathrm{v} / \mathrm{v}$ of total aqueous phase. Our preliminary experiment also showed that the TCS concentration in the absence of methanol could achieve $25 \mathrm{mg} \mathrm{L}^{-1}$, which was analyzed by ultraviolet and visible spectroscopy. Three initial concentrations of 25,5 , and $1 \mathrm{mg} \mathrm{L}^{-1}$ for TCS respectively were mixed with CA fibers by end-over-end rotation in a dark, temperature-controlled room. After desired time intervals, solid adsorbent fibers were separated from the liquid phase using clinical tweezers, after which $1 \mathrm{~mL}$ of decanted solution was filtered using a $0.2 \mu \mathrm{m}$ PTFE membrane filter for analysis of TCS concentration. To obtain adsorption isotherm curves, the initial concentration of TCS was fixed at $25 \mathrm{mg} \mathrm{L}^{-1}$, and from 4 to $40 \mathrm{mg}$ of 
CA fibers were mixed with these $40 \mathrm{~mL}$ TCS-containing solutions at $298 \mathrm{~K}$, respectively.

TCS Analysis. The concentration of TCS was determined by an Agilent 1100 high performance liquid chromatography system with a $\mathrm{C} 18$ column at $298 \mathrm{~K}$. The wavelength of the ultraviolet detector was set at $280 \mathrm{~nm}$, and the sample injection volume was $50 \mu \mathrm{L}$. The mobile phase was mixture of HPLC-grade methanol and ultrapure water with a volume ratio of $90: 10$, which was delivered at a rate of $1.0 \mathrm{~mL} \mathrm{~min}^{-1}$ through the column.

\section{RESULTS AND DISCUSSION}

Preparation and Morphological Characterization of CA Fibers. During the electrospinning process, solvents determine the characteristics of fibers converted from the CA powders. Even though CA powders dissolved in single-solvent systems of chloroform, dimethylformamide, or acetone could form a homogeneous clear solution, discrete beads instead of fibers were obtained (Supporting Information Figure S1). To improve the electrospinnability of CA solutions, the chloroform/methanol mixed system was adopted because methanol has a much higher boiling point and dielectric constant than pure chloroform. ${ }^{7}$ Even so, because the intrinsically high viscosity of $\mathrm{CA}$ solution in the electrospun process was prolonged, the remaining CA solution was difficult to spin due to the clogging problem. As in previous reports, ${ }^{33,34}$ the presence of inorganic ions existing in precursor solutions was highly beneficial to fiber formation during the spray process. $\mathrm{BMIPF}_{6}$, which consists of organic cations and inorganic anions, exhibited much better compatibility and solubility in organic solution than inorganic salts. Thus, the introduction of $\mathrm{BMIPF}_{6}$ for morphological control of CA fibers and films was more desirable.

Based on experimental results, a continuous electrospinning process was achieved with the $\mathrm{BMIPF}_{6}$-containing solution, in contrast to the occurrence of severe clogging after several seconds without the addition of IL. This was attributed to the amplified electric force caused by adding ionic liquid. The CA solution was swiftly converted to the fibers as soon as a Taylor cone appeared at the tip of the blunt needle, thereby keeping the CA-solution near the needle region rather than exposing it to air. Thus, the clogging problem was inhibited successfully (Scheme 1). Figure 1a shows an SEM image of CA ribbon-like fibers after the electrospinning process. The as-spun fibers were $100-400 \mathrm{~nm}$ in diameter and up to tens of centimeters long. The coarse surfaces of as-spun fibers mainly resulted from the evaporation of the polar organic solvents during the production process, and this structure provided a larger pore volume, which can be accessed readily by reactant molecules. The porosity of the fibers was revealed, with existence of evenly distributed pores inside the nanofibers (Figure $1 \mathrm{~b}$ ). These results were confirmed by the nitrogen adsorption-desorption measurements, which indicated the presence of uniform pores with an average diameter of $3 \mathrm{~nm}$. In addition, compared to the powder form, the pore volume of fibers increased from 0.0256 to $0.0655 \mathrm{~cm}^{3} \mathrm{~g}^{-1}$ (Supporting Information Figure S2).

Kinetics and Isotherm of TCS Adsorption onto CA Fibers. Adsorption kinetics of TCS onto CA fibers at the $\mathrm{pH}=$ 7 condition are presented in Figure 2a. The concentrations of TCS dropped rapidly (90\%, 85\%, and $78 \%$ ) in first 5 min and thoroughly separated from aqueous environment within 10, 30, and $120 \mathrm{~min}$, corresponding to the initial concentrations at 1,5 , and $25 \mathrm{mg} \mathrm{L}^{-1}$, respectively. The results of ultraviolet and visible spectroscopy demonstrated that our adsorbent released little in the way of undesirable substances into the environment

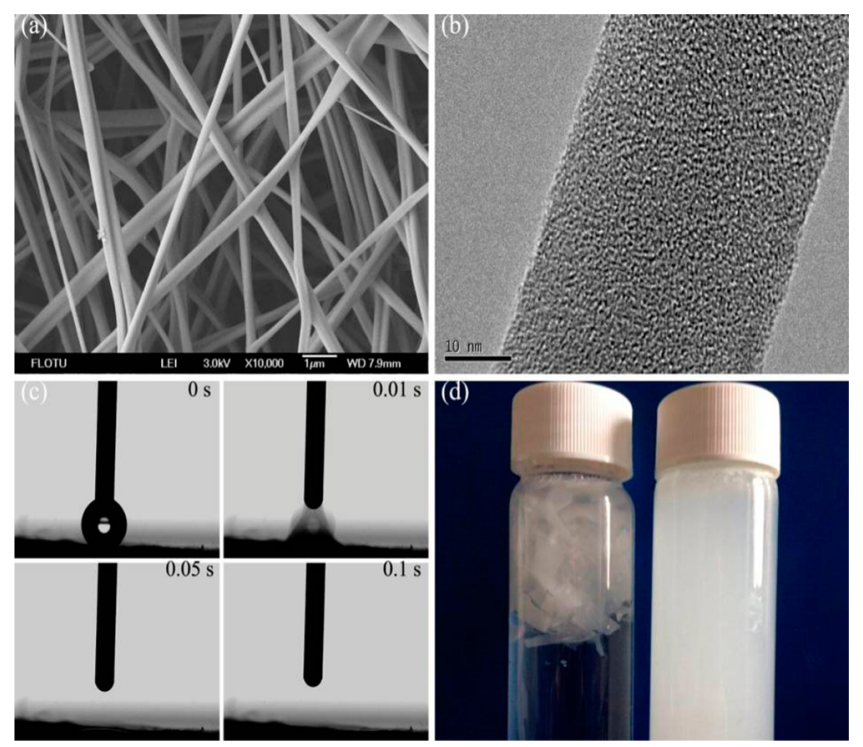

Figure 1. (a) SEM and (b) HREM images of the as-spun CA fibers; (c) photographs taken during WCA measurements; (d) fiber and powder form of CA immersed in water for 30 days.

(Supporting Information Figure S3). The kinetics results indicated that CA fibers possess strong affinity for TCS. In addition, the pseudo-first-order model and pseudo-secondorder model were employed to fit the kinetic data. The correlation coefficient $\left(R^{2}=0.982\right)$ for the pseudo-first-order model was lower than that of the pseudo-second-order model $\left(R^{2}=0.999\right)$ (Supporting Information Figure S4). Furthermore, the experimental adsorption capacity of CA fibers $(25 \mathrm{mg}$ $\mathrm{g}^{-1}$ ) approached the theoretical value calculated by the pseudosecond-order model $\left(24.8 \mathrm{mg} \mathrm{g}^{-1}\right)$, indicating that the pseudosecond-order model better fits TCS adsorption onto CA fibers. In addition, compared to the powder form, CA fibers exhibited much higher adsorption capacity to TCS (Supporting Information Figure S5), which can be ascribed to the larger specific area and the enhanced surface hydrophilicity of the CA fibers. As shown in Figure 1c, the hydrophilic character of CA fibers could facilitate the diffusion of solution into the larger internal network of spaces via capillary action. Therefore, the increased contact area between the CA fibers and solution promoted the adsorption of dissolved TCS molecules onto CA. Furthermore, the CA membrane consisted of fibers maintaining their original structure after immersion in water for about 30 days, which benefits the practical usage in contrast to powder form (Figure 1d).

The adsorption isotherm of TCS onto CA fibers is shown in Figure $2 \mathrm{~b}$. The Langmuir model $\left(R^{2}=0.971\right)$ exhibited a better fit for the TCS isotherm of CA fibers compared to the Freundlich model $\left(R^{2}=0.918\right)$. As Langmuir model is based on sorbents with homogeneous sorption sites on the surface, the result suggested the fibers may possess specific sorption sites for TCS. In addition, comparing with the TCS adsorption capacities $\left(Q_{m}\right)$ of various adsorbents (Table 1$)$, the performance of CA fibers $\left(797.7 \mathrm{mg}^{-1} \mathrm{~g}^{-1}\right)$ was better than the materials in pertinent literature.

Effect of pH on TCS Sorption. As an important variable factor, the effect of $\mathrm{pH}$ on TCS adsorption by CA fibers was investigated, and the results are shown in Figure 2c. The results demonstrate that the TCS adsorption capacity of the CA fibers showed no evident variation in the $\mathrm{pH}$ range from 2.0 to 7.0, 
(a)
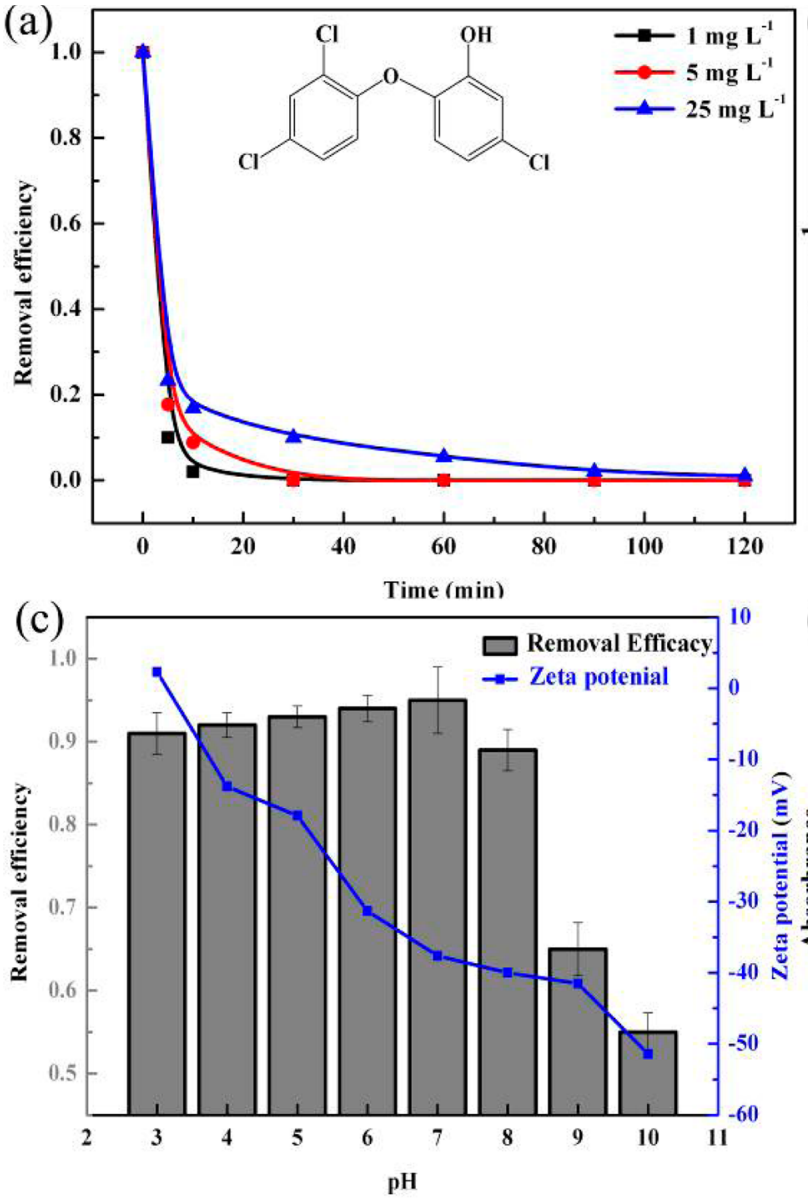

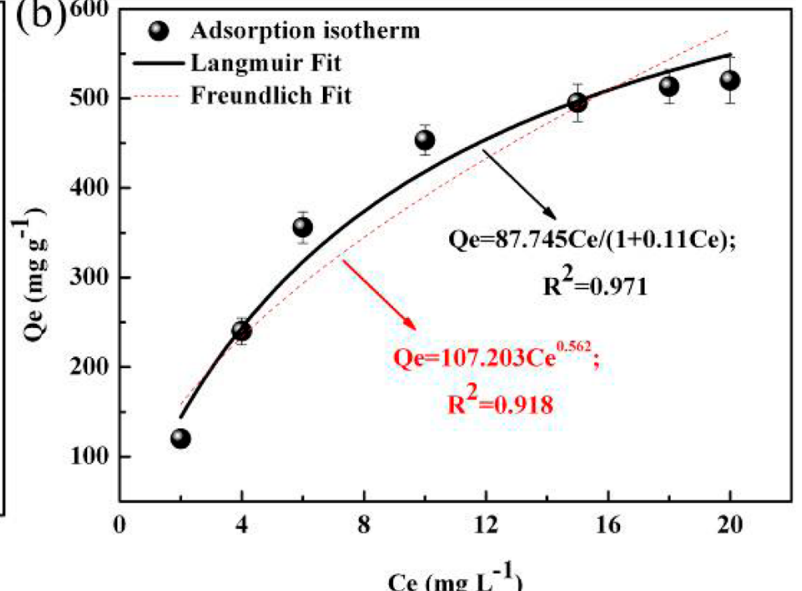

(d)

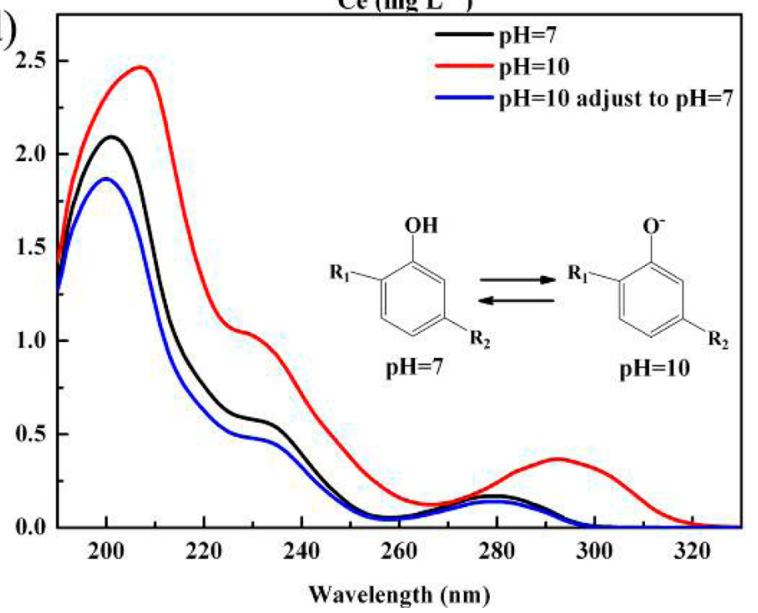

Figure 2. (a) Removal efficiency of TCS at different initial concentrations by CA fibers with a dosage of $1 \mathrm{~g} \mathrm{~L}^{-1}$. Graph is plotted as the normalized concentration change versus time for different samples. (b) Adsorption isotherm of TCS sorption onto CA fibers at $298 \mathrm{~K}$ and $\mathrm{pH}=7 \pm 0.2$. (c) Effect of solution $\mathrm{pH}$ on TCS sorption onto CA fibers (initial TCS concentration was $25 \mathrm{mg} \mathrm{L} \mathrm{L}^{-1}$, adsorption time was 60 min) and the corresponding zeta potential. (d) UV-vis spectrometry results of TCS under neutral and alkaline conditions.

Table 1. Maximum TCS Adsorption Capacity $\left(Q_{m}\right)$ of Various Adsorbents

\begin{tabular}{|c|c|c|c|c|c|}
\hline adsorbents & $\underset{\left.\mathrm{g}^{-1}\right)}{\mathrm{Q}_{\mathrm{m}}\left(\mathrm{mg}^{-1}\right.}$ & $\begin{array}{c}T \\
(\mathrm{~K})\end{array}$ & model & $R^{2}$ & refs \\
\hline activated carbon & 67.11 & 298 & Langmuir & 0.92 & 28 \\
\hline kaolinite & 6.03 & 298 & Langmuir & 0.96 & 28 \\
\hline montmorillonite & 1.79 & 298 & Langmuir & 0.99 & 28 \\
\hline$\gamma-\mathrm{Fe}_{2} \mathrm{O}_{3} /$ carbon & $\begin{array}{r}170.90- \\
763.81\end{array}$ & 298 & Langmuir & 0.99 & 29 \\
\hline carbon nanotubes & $\begin{array}{r}105.02- \\
558.26\end{array}$ & 298 & $\begin{array}{l}\text { Polanyi } \\
\text { Manes }\end{array}$ & 0.99 & 30 \\
\hline CA fibers & 797.7 & 298 & Langmuir & 0.97 & $\begin{array}{l}\text { This } \\
\text { study }\end{array}$ \\
\hline
\end{tabular}

whereas it declined swiftly at $\mathrm{pH}$ above 8.0. This observation could be explained by the potential effects of $\mathrm{pH}$ variation on the TCS adsorption process. TCS could be considered a weak organic acid $\left(\mathrm{p} K_{\mathrm{a}}=8.14\right)$, which exists in the protonated form in acid and neutral conditions, or ionized forms in alkaline condition according to UV-vis spectrometry results (Figure 2d). Generally, H-bonding was the principal mechanism controlling adsorption of TCS onto CA fibers under acidic and neutral conditions (discussion in next section). By contrast, as $\mathrm{pH}$ increased, the surface charge density of CA fibers became more negative (Figure 2c). Simultaneously, TCS molecules were in deprotonated form at $\mathrm{pH}$ higher than its $\mathrm{p} K_{\mathrm{a}}$ value.
Consequently, when the $\mathrm{pH}$ value exceeded 8.0, the electrostatic repulsion between the negatively charged TCS species and surface of CA fibers hindered the adsorption, corresponding to the deterioration in performance.

Adsorption Mechanism of TCS onto CA Fibers. Effect of Functional Groups of Adsorbent. To gain insight into the superior performance of the CA fibers in adsorbing TCS, it is necessary to determine the chemical composition of the CA fibers. As can be seen from Figure 3a, the FTIR spectrum exhibits a characteristically strong carbonyl absorption peak at $1750 \mathrm{~cm}^{-1}$ attributed to the acetyl groups, a hydroxyl peak centering on $3500-3600 \mathrm{~cm}^{-1}$, and an ether peak at 1648 $\mathrm{cm}^{-1} \cdot{ }^{35-39}$ Peaks assigned to $\mathrm{C}-\mathrm{H}$ bending vibrations appeared at 1452 and $1493 \mathrm{~cm}^{-1} \cdot{ }^{40,41}$ Meanwhile, characteristic peaks of BMIPF $_{6}$ at 834,623 , and $1172 \mathrm{~cm}^{-1}$ were found in spectra. ${ }^{42-44}$ The ${ }^{13} \mathrm{C}$ NMR measurements of CA fibers are shown in Figure 3b. Signals were observed a 20, 64, and 170 ppm corresponding to $-\mathrm{CH}_{3}(\mathrm{C}-8),-\mathrm{CH}_{2} \mathrm{O}-(\mathrm{C}-6)$, and $-\mathrm{C}=\mathrm{O}(\mathrm{C}-7)$, respectively. ${ }^{45,46}$ The peaks appearing at $75-$ $100 \mathrm{ppm}$ were attributed to $-\mathrm{C}-\mathrm{O}-\mathrm{C}(\mathrm{C}-1, \mathrm{C}-2$, and $\mathrm{C}-4)$ as well as $-\mathrm{C}-\mathrm{OH}(\mathrm{C}-3){ }^{47}$

In order to investigate the strong binding interaction between TCS and CA fibers, TCS-saturated CA fibers were analyzed by SEM, NMR, FTIR, and XPS. It could be seen that the coarse surface of the original CA fibers became smooth after absorption due to uniform coating by TCS, and the EDS 

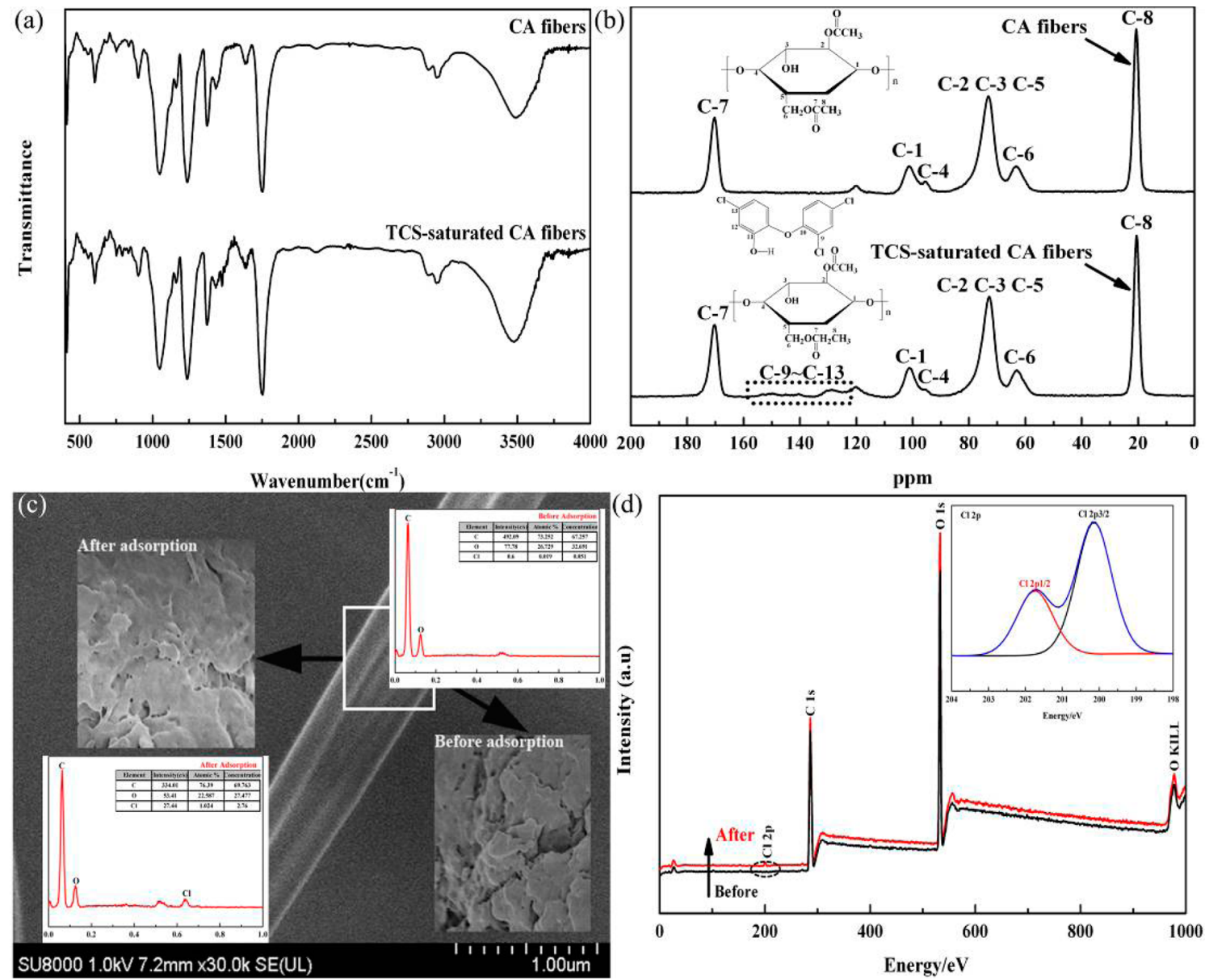

Figure 3. (a) FTIR and (b) NMR of CA fibers before and after adsorption of TCS; (c) FESEM of a single CA fiber before and after adsorption with the corresponding EDS results (inset); (d) X-ray photoelectron spectra of CA fibers.

images further confirmed this conclusion (Figure 3c). FTIR revealed peaks of TCS (Supporting Information Figure S6) added to the original characteristic peaks of CA fibers without generating any shifts. Furthermore, the NMR analysis results exhibited some new peaks ranging from 120 to $160 \mathrm{ppm}$ (Figure $3 \mathrm{~b})$, which arose from the adsorbed TCS. In addition, the $-\mathrm{C}-$ $\mathrm{O}-\mathrm{C}$ (C-4) peak showed a chemical shift compared to the pristine CA fibers. The XPS analysis indicated that the TCSchlorine bond in TCS-loaded CA fibers had a binding energy of $201 \mathrm{eV}$ (Figure 3d).

To identify the functional groups of CA fibers involved in the adsorption process, we converted modified CA and low acetyl content CA (30\%) powders to fibers respectively by electrospinning as substitutes for the original CA fibers, namely, modified- and low acetyl- CA fibers. As described in Section S2 (Supporting Information), the modified CA was prepared by an initial redox reaction between cerium ions (IV) and $-\mathrm{C}-\mathrm{OH}$ groups on the surface of $\mathrm{CA}$, which resulted in the formation of free radicals, and then PEGMA monomers were added into the reaction system in order to graft a block-like structure onto those carbon atoms. The peaks of $\mathrm{C}-3$ and its neighboring carbon atoms (C-2, C-4) appeared higher chemical shifts after modifying, which generated by the graft of electrodonating groups on the C-3 position (Supporting Information Figure S7). Furthermore, because of introduction of the electrodonating groups on these carbon atoms, the hydrogen bond between intramolecular was promoted, thereby impairing the activity of these hydroxyls toward TCS. ${ }^{48}$ Moreover, a relatively decent peak area of carbonyl carbons was observed in the low acetyl-CA fibers. As shown in Figure 4a, the adsorption capacity of TCS onto modified and low acetyl CA fibers suffered degradation, to $67 \%$ and $40 \%$ removal, respectively. Therefore, we proposed that the hydroxyl and carbonyl groups play pivotal roles in the adsorption process. In addition, in view of the higher adsorption capacity of CA fibers compared to activated carbon or other materials with abundant numbers of these groups, ${ }^{28}$ the possibility of synergistic effects between the functional groups and the molecular structure of the CA fibers should be studied in depth.

Effect of Functional Groups of Adsorbate. Besides the functional groups in the CA fibers, the molecular structure of TCS should be considered in the adsorption process. The TCS molecule can be considered a metachlorine and para-odichlorophenoxy substituted phenol. Substituents on the aromatic ring affect the reactivity of phenol by electronic and steric effects. ${ }^{49}$ Electron-withdrawing substituents decrease the electron density of the benzene ring and, hence, make the hydrogen atom more positive. When a chlorine atom substitutes for a hydrogen atom in a benzene ring, the chlorine usually draws electrons in the $\mathrm{C}-\mathrm{Cl}$ bond toward itself. The net result of these two opposing effects is electron-withdrawing. ${ }^{50}$ Therefore, we surmised that as the number of chlorine atoms increases, the hydrogen atom of a phenol functional group is expected to become more positive, and thus would form a hydrogen bond with the carbonyl groups of CA more readily. ${ }^{51}$ 

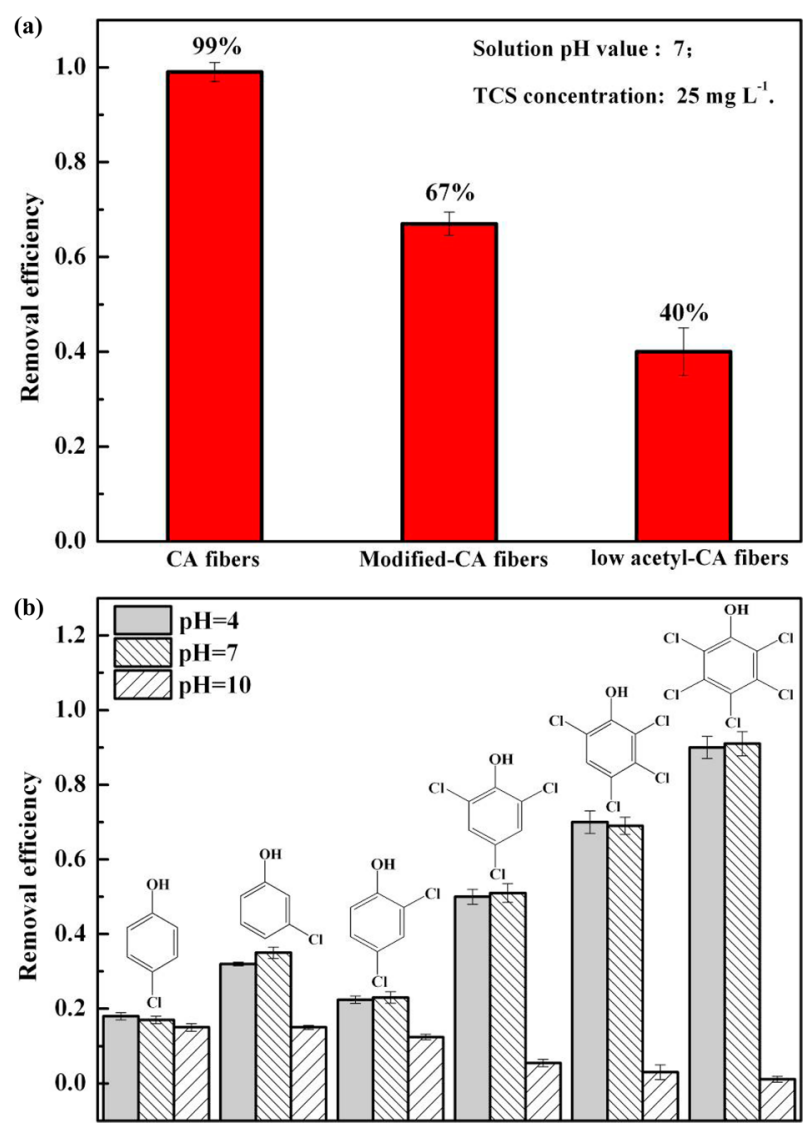

Figure 4. (a) Removal efficiency of TCS by CA, modified and low acetyl CA fibers (the dosage of adsorbents was $1.0 \mathrm{~g} \mathrm{~L}^{-1}$; initial chlorophenols concentration was $25 \mathrm{mg} \mathrm{L}^{-1}$; $4 \mathrm{~h}$ allowed for attaining adsorption equilibrium). (b) Removal efficiency of chlorophenols by CA fibers at $\mathrm{pH}=4, \mathrm{pH}=7$, and $\mathrm{pH}=10$ (the dosage of adsorbents was $1.0 \mathrm{~g} \mathrm{~L}^{-1}$; initial chlorophenols concentration was $25 \mathrm{mg} \mathrm{L}^{-1}$; $4 \mathrm{~h}$ allowed for achieving adsorption equilibrium).

To confirm the role of electron-withdrawing substituents in the adsorption process and verify the conjectures mentioned above, 2-chlorophenol, 3-chlorophenol, 2,4-dichlorophenol, 2,4,6-trichlorophenol, 2,3,4,6-tetrachlorophenol, and pentachlorophenol in aqueous solutions were adsorbed by CA fibers, respectively. As shown in Figure 4b, the adsorption capacity of CA fibers showed a generally growing trend as chlorine atom substitution increased. This trend agreed well with the theoretical predictions based on hydrogen bonding theory. An exception to the general trend was the higher adsorption capacity of CA fibers for the meta-chlorophenol compared with ortho-chlorophenol and dichlorophenol. It was reasonable to propose that the meta-chlorine atom played more a critical role than the para- and ortho-chlorine atoms of chlorophenol during adsorption, while the exact role of the meta-chlorine substituent remains to be elucidated by structural as well as computational studies. Similar to chlorine substituents, the para-o-dichlorophenoxy (ester) group of TCS also had an electronwithdrawing effect on the phenol. ${ }^{52}$ Hence, the phenol group of TCS was expected to readily form a hydrogen bond with carbonyl and hydroxyl groups of CA. In addition, the steric effects generated by substitution of a para-o-dichlorophenoxy group on the adsorption performance should not be ignored. The substituent added a non-coplanar benzene ring, which complicated the molecular structure from planar to non-planar. However, the non-planar structure reduced the chance of breaking $\mathrm{H}$ bonds between water molecules, resulting in its lack of stability in aqueous solution. Therefore, compared to these chlorophenol molecules with the coplanar structures, TCS molecules exhibited stronger affinity toward the CA fibers.

\section{CONCLUSIONS}

The CA fibers obtained via electrospinning exhibited a high capacity for aqueous removal of TCS. The adsorption results indicated the physical-chemical surface of the CA fibers, the chemical properties of the TCS, and the aqueous conditions that are all factors in the TCS sorption onto the CA fibers. The combination of cellulose acetate's relatively low cost and the high separability of fibers from aqueous solution in a membrane consisting of these CA fibers has great potential for use in a scalable water treatment.

\section{ASSOCIATED CONTENT}

S Supporting Information

Adsorption isotherm and kinetics models (Section S1); the modification process of CA (Section S2); SEM images of the other CA solutions after electrospinning (Figure S1); nitrogen adsorption isotherms of the CA fibers and powders (Figure S2). UV-vis spectroscopy of TCS solution mixed with fibers at different intervals (Figure S3); pseudo first- and second-order kinetic models employed to represent the adsorption process (Figure S4); adsorptive performances of CA powders and fibers (Figure S5); FTIR spectra of TCS (Figure S6); ${ }^{13} \mathrm{C} \mathrm{CP} / \mathrm{MAS}$ spectra of the modified and low acetyl CA fibers (Figure S7).This material is available free of charge via the Internet at http://pubs.acs.org.

\section{AUTHOR INFORMATION}

\section{Corresponding Authors}

*E-mail: hjliu@rcees.ac.cn.

*E-mail: jhli@mail.tsinghua.edu.cn.

\section{Notes}

The authors declare no competing financial interest.

\section{ACKNOWLEDGMENTS}

This work was supported by the National Science Fund for Distinguished Young Scholars of China (Grant No. 51225805) and the National High Technology Research and Development Program of China (Grants No. 2011CB935704, 2012AA062606).

\section{REFERENCES}

(1) Klemm, D.; Heublein, B.; Fink, H. P.; Bohn, A. Cellulose: Fascinating Biopolymer and Sustainable Raw Material. Angew. Chem., Int. Ed. 2005, 44, 3358-3393.

(2) Huang, C.; Soenen, S. J.; Rejman, J.; Lucas, B.; Braeckmans, K.; Demeester, J.; De Smedt, S. C. Stimuli-Responsive Electrospun Fibers and their Applications. Chem. Soc. Rev. 2011, 40, 2417-2434.

(3) Greiner, A.; Wendorff, J. H. Electrospinning: A Fascinating Method for the Preparation of Ultrathin Fibres. Angew. Chem., Int. Ed. 2007, 46, 5670-5703.

(4) Crespy, D.; Friedemann, K.; Popa, A.M. Colloid-Electrospinning: Fabrication of Multicompartment Nanofibers by the Electrospinning of Organic or/and Inorganic Dispersions and Emulsions. Macromol. Rapid Commun. 2012, 33, 1978-1995.

(5) Zhang, C. L.; Yu, S. H. Nanoparticles Meet Electrospinning: Recent Advances and Future Prospects. Chem. Soc. Rev. 2014, 43, 4423-4448.

(6) Wang, J.; Yao, H. B.; He, D.; Zhang, C. L.; Yu, S. H. Facile Fabrication of Gold Nanoparticles-Poly(vinyl alcohol) Electrospun 
Water-Stable Nanofibrous Mats: Efficient Substrate Materials for Biosensors. ACS Appl. Mater. Interfaces 2012, 4, 1963-1971.

(7) Tungprapa, S.; Puangparn, T.; Weerasombut, M.; Jangchud, I.; Fakum, P.; Semongkhol, S.; Meechaisue, C.; Supaphol, P. Electrospun Cellulose Acetate Fibers: Effect of Solvent System on Morphology and Fiber Diameter. Cellulose 2007, 14, 563-575.

(8) Liu, H. Q.; Hsieh, Y. L. Ultrafine Fibrous Cellulose Membranes from Electrospinning of Cellulose Acetate. J. Polym. Sci., Part B: Polym. Phys. 2002, 40, 2119-2129.

(9) Son, W. K.; Youk, J. H.; Lee, T. S.; Park, W. H. Electrospinning of Ultrafine Cellulose Acetate Fibers: Studies of a New Solvent System and Deacetylation of Ultrafine Cellulose Acetate Fibers. J. Polym. Sci, Part B: Polym. Phys. 2004, 42, 5-11.

(10) Lu, X.; Zhou, J.; Zhao, Y.; Qiu, Y.; Li, J. Room Temperature Ionic Liquid Based Polystyrene Nanofibers with Superhydrophobicity and Conductivity Produced by Electrospinning. Chem. Mater. 2008, 20, 3420-3424.

(11) Freire, M. G.; Teles, A. R. R.; Ferreira, R. A. S.; Carlos, L. D.; Lopes-da-Silva, J. A.; Coutinho, J. A. P. Electrospun Nanosized Cellulose Fibers Using Ionic Liquids at Room Temperature. Green Chem. 2011, 13, 3173-3180.

(12) Hardelin, L.; Perzon, E.; Hagstrom, B.; Walkenstrom, P.; Gatenholm, P. Influence of Molecular Weight and Rheological Behavior on Electrospinning Cellulose Nanofibers from Ionic Liquids. J. Appl. Polym. Sci. 2013, 130, 2303-2310.

(13) Lu, X. B.; Hu, J. Q.; Yao, X.; Wang, Z. P.; Li, J. H. Composite System Based on Chitosan and Room-Temperature Ionic Liquid: Direct Electrochemistry and Electrocatalysis of Hemoglobin. Biomacromolecules 2006, 7, 975-980.

(14) Buzzeo, M. C.; Hardacre, C.; Compton, R. G. Use of Room Temperature Ionic Liquids in Gas Sensor Design. Anal. Chem. 2004, 76, 4583-4588.

(15) Halden, R. U. On the Need and Speed of Regulating Triclosan and Triclocarban in the United States. Environ. Sci. Technol. 2014, 48, 3603-3611.

(16) Chen, X.; Richard, J.; Liu, Y.; Dopp, E.; Tuerk, J.; Bester, K. Ozonation Products of Triclosan in Advanced Wastewater Treatment. Water. Res. 2012, 46, 2247-2256.

(17) Anger, C. T.; Sueper, C.; Blumentrit, D. J.; McNeill, K.; Engstrom, D. R.; Arnold, W. A. Quantification of Triclosan, Chlorinated Triclosan Derivatives, and their Dioxin Photoproducts in Lacustrine Sediment Cores. Environ. Sci. Technol. 2013, 47, 18331843.

(18) Clayton, E. M. R.; Todd, M.; Dowd, J. B.; Aiello, A. E. The Impact of Bisphenol A and Triclosan on Immune Parameters in the U.S. Population, NHANES 2003-2006. Environ. Health. Persp. 2011, 119, 390-396.

(19) Savage, J. H.; Matsui, E. C.; Wood, R. A.; Keet, C. A. Urinary Levels of Triclosan and Parabens are Associated with Aeroallergen and Food Sensitization. J. Allergy Clin. Immunol. 2012, 130, 453-+.

(20) Bertelsen, R. J.; Longnecker, M. P.; Lovik, M.; Calafat, A. M.; Carlsen, K. H.; London, S. J.; Carlsen, K. C. L. Triclosan Exposure and Allergic Sensitization in Norwegian Children. Allergy 2013, 68, 84-91.

(21) Sicherer, S. H.; Leung, D. Y. M. Advances in Allergic Skin Disease, Anaphylaxis, and Hypersensitivity Reactions to Foods, Drugs, and Insects in 2012. J. Allergy Clin. Immunol. 2013, 131, 55-66.

(22) Daughton, C. G.; Ternes, T. A. Pharmaceuticals and Personal Care Products in the Environment: Agents of Subtle Change? Environ. Health. Persp. 1999, 107, 907-938.

(23) Ternes, T. A.; Meisenheimer, M.; McDowell, D.; Sacher, F.; Brauch, H. J.; Gulde, B. H.; Preuss, G.; Wilme, U.; Seibert, N. Z. Removal of Pharmaceuticals during Drinking Water Treatment. Environ. Sci. Technol. 2002, 36, 3855-3863.

(24) Liu, H.; Cao, X.; Liu, G.; Wang, Y.; Zhang, N.; Li, T.; Tough, R. Photoelectrocatalytic Degradation of Triclosan on $\mathrm{TiO}_{2}$ Nanotube Arrays and Toxicity Change. Chemosphere 2013, 93, 160-165.

(25) Rafqah, S.; Wong-Wah-Chung, P.; Nelieu, S.; Einhorn, J.; Sarakha, M. Phototransformation of Triclosan in the Presence of $\mathrm{TiO}_{2}$ in Aqueous Suspension: Mechanistic Approach. Appl. Catal., B 2006, 66, 119-125.

(26) Aranami, K.; Readman, J. W. Photolytic Degradation of Triclosan in Freshwater and Seawater. Chemosphere 2007, 66, 10521056.

(27) Westerhoff, P.; Yoon, Y.; Snyder, S.; Wert, E. Fate of EndocrineDisruptor, Pharmaceutical, and Personal Care Product Chemicals during Simulated Drinking Water Treatment Processes. Environ. Sci. Technol. 2005, 39, 6649-6663.

(28) Behera, S. K.; Oh, S. Y.; Park, H. S. Sorption of Triclosan onto Activated Carbon, Kaolinite and Montmorillonite: Effects of $\mathrm{pH}$, Ionic Strength, and Humic Acid. J. Hazard. Mater. 2010, 179, 684-691.

(29) Zhu, X.; Liu, Y.; Luo, G.; Qian, F.; Zhang, S.; Chen, J. Facile Fabrication of Magnetic Carbon Composites from Hydrochar via Simultaneous Activation and Magnetization for Triclosan Adsorption. Environ. Sci. Technol. 2014, 48, 5840-8.

(30) Cho, H.-H.; Huang, H.; Schwab, K. Effects of Solution Chemistry on the Adsorption of Ibuprofen and Triclosan onto Carbon Nanotubes. Langmuir 2011, 27, 12960-12967.

(31) Baracs, J.; Huszar, O.; Sajjadi, S. G.; Horvath, O. P. Surgical Site Infections after Abdominal Closure in Colorectal Surgery Using Triclosan-Coated Absorbable Suture (PDS Plus) vs. Uncoated Sutures (PDS II): A Randomized Multicenter Study. Surg. Infect. 2011, 12, 483-489.

(32) Liang, X.; Chen, W.; Sun, G.; Liu, S.; Cai, H.; Zhou, L. Experimental Study on New Self and Mutual-Aiding Occlusive Dressing for Wound. Chin. Med. J. 2014, 127, 1321-1327.

(33) Zong, X. H.; Kim, K.; Fang, D. F.; Ran, S. F.; Hsiao, B. S.; Chu, B. Structure and Process Relationship of Electrospun Bioabsorbable Nanofiber Membranes. Polymer 2002, 43, 4403-4412.

(34) Moghe, A. K.; Hufenus, R.; Hudson, S. M.; Gupta, B. S. Effect of the Addition of a Fugitive Salt on Electrospinnability of Poly(epsiloncaprolactone). Polymer 2009, 50, 3311-3318.

(35) Biniak, S.; Szymanski, G.; Siedlewski, J.; Swiatkowski, A. The Characterization of Activated Carbons with Oxygen and Nitrogen Surface Groups. Carbon 1997, 35, 1799-1810.

(36) Si, Y.; Samulski, E. T. Synthesis of Water Soluble Graphene. Nano Lett. 2008, 8, 1679-1682.

(37) Ilharco, L. M.; de Barros, R. B. Aggregation of Pseudoisocyanine Iodide in Cellulose Acetate Films: Structural Characterization by FTIR. Langmuir 2000, 16, 9331-9337.

(38) Dias, C. R.; Rosa, M. J.; de Pinho, M. N. Structure of Water in Asymmetric Cellulose Ester Membranes -An ATR-FTIR Study. J. Membr. Sci. 1998, 138, 259-267.

(39) Li, J.; Vadahanambi, S.; Kee, C. D.; Oh, I. K. Electrospun Fullerenol-Cellulose Biocompatible Actuators. Biomacromolecules 2011, 12, 2048-2054.

(40) Maeda, Y.; Nakamura, T.; Ikeda, I. Changes in the Hydration States of Poly(N-alkylacrylamide)s during their Phase Transitions in Water Observed by FTIR Spectroscopy. Macromolecules 2001, 34, 1391-1399.

(41) Sato, H.; Murakami, R.; Padermshoke, A.; Hirose, F.; Senda, K.; Noda, I.; Ozaki, Y. Infrared Spectroscopy Studies of CH Center Dot Center Dot Center Dot O Hydrogen Bondings and Thermal Behavior of Biodegradable Poly(hydroxyalkanoate). Macromolecules 2004, 37, $7203-7213$.

(42) Zhao, Q.; Zhan, D. P.; Ma, H. Y.; Zhang, M. Q.; Zhao, Y. F.; Jing, P.; Zhu, Z. W.; Wan, X. H.; Shao, Y. H.; Zhuang, Q. K. Direct Proteins Electrochemistry Based on Ionic Liquid Mediated Carbon Nanotube Modified Glassy Carbon Electrode. Front. Biosci. 2005, 10, 326-334.

(43) Jiang, J.; Gao, D.; Li, Z.; Su, G. Gel Polymer Electrolytes Prepared by in situ Polymerization of Vinyl Monomers in RoomTemperature Ionic Liquids. React. Funct. Polym. 2006, 66, 1141-1148.

(44) Li, D.; Pang, Z.; Wang, Q.; Ke, H.; Cai, Y.; Xu, Y.; Huang, F.; Wei, Q. Fabrication and Characterization of Polyamide6-Room Temperature Ionic Liquid (PA6-RTIL) Composite Nanofibers by Electrospinning. Fiber. Polym. 2013, 14, 1614-1619. 
(45) Wishart, D. S.; Bigam, C. G.; Holm, A.; Hodges, R. S.; Sykes, B. D. H-1, C-13 and N-15 Random Coil NMR Chemical-Shifts of the Common Amino-Acids.1. Investigations of Nearest-Neighbor Effects. J. Biomol. NMR 1995, 5, 67-81.

(46) Remsing, R. C.; Swatloski, R. P.; Rogers, R. D.; Moyna, G. Mechanism of Cellulose Dissolution in the Ionic Liquid 1-N-Butyl-3Methylimidazolium Chloride: a C-13 and Cl-35/37 NMR Relaxation Study on Model Systems. Chem. Commun. 2006, 1271-1273.

(47) Chen, W.; Su, Y.; Peng, J.; Dong, Y.; Zhao, X.; Jiang, Z. Engineering a Robust, Versatile Amphiphilic Membrane Surface Through Forced Surface Segregation for Ultralow Flux-Decline. Adv. Funct. Mater. 2011, 21, 191-198.

(48) Moorthy, N. S. H. N.; Cerqueira, N. S.; Ramos, M. J.; Fernandes, P. A. QSAR Analysis of 2-Benzoxazolyl Hydrazone Derivatives for Anticancer Activity and Its Possible Target Prediction. Med. Chem. Res. 2012, 21, 133-144.

(49) Zhang, H.; Huang, C. H. Oxidative Transformation of Triclosan and Chlorophene by Manganese Oxides. Environ. Sci. Technol. 2003, 37, 2421-2430.

(50) Swain, C. G.; Lupton, E. C. Field and Resonance Components of Substituent Effects. J. Am. Chem. Soc. 1968, 90, 4328-4337.

(51) Ahn, D.-S.; Park, S. W.; Lee, S.; Kim, B. Effects of Substituting Group on the Hydrogen Bonding in Phenol- $\mathrm{H}_{2} \mathrm{O}$ Complexes: $\mathrm{Ab}$ Initio Study. J. Phys. Chem. A 2002, 107, 131-139.

(52) Auffrant, A.; Prim, D.; Rose-Munch, F.; Rose, E.; Vaissermann, J. First Synthesis of Cationic $\left[(\eta 6\right.$-arene $\left.) \mathrm{Mn}(\mathrm{CO})_{3}\right]$ Complexes Substituted by Resonance Electron Withdrawing Groups. Organometallics 2001, 20, 3214-3216. 